\title{
WestVirginiaUniversity
}

THE RESEARCH REPOSITORY @ WVU

Graduate Theses, Dissertations, and Problem Reports

2000

\section{Improving commercial vehicle crash data quality in West Virginia}

Kris Sean Gillespie

West Virginia University

Follow this and additional works at: https://researchrepository.wvu.edu/etd

\section{Recommended Citation}

Gillespie, Kris Sean, "Improving commercial vehicle crash data quality in West Virginia" (2000). Graduate Theses, Dissertations, and Problem Reports. 1072.

https://researchrepository.wvu.edu/etd/1072

This Thesis is protected by copyright and/or related rights. It has been brought to you by the The Research Repository @ WVU with permission from the rights-holder(s). You are free to use this Thesis in any way that is permitted by the copyright and related rights legislation that applies to your use. For other uses you must obtain permission from the rights-holder(s) directly, unless additional rights are indicated by a Creative Commons license in the record and/ or on the work itself. This Thesis has been accepted for inclusion in WVU Graduate Theses, Dissertations, and Problem Reports collection by an authorized administrator of The Research Repository @ WVU. For more information, please contact researchrepository@mail.wvu.edu. 


\title{
Improving Commercial Vehicle Crash Data Quality in West Virginia
}

\author{
Kris S. Gillespie \\ Thesis submitted to the \\ College of Engineering and Mineral Resources \\ at West Virginia University \\ in partial fulfillment of the requirements \\ for the degree of \\ Master of Science \\ in \\ Civil and Environmental Engineering \\ Gary Winn, Ph.D., IMSE, Co-Chair \\ Hema Siriwardane, Ph.D., CEE, Co-Chair \\ Ronald Eck, Ph.D., CEE \\ L. James French, Ph.D., P.E., CEE \\ Department of Civil and Environmental Engineering \\ Morgantown, WV \\ 2000
}

Keywords: highway safety; traffic accidents; crash data; commercial vehicles

Copyright 2000 Kris S. Gillespie 


\section{ABSTRACT \\ Improving Commercial Vehicle Crash Data Quality in West Virginia}

Kris S. Gillespie

The purpose of this study was to identify methods to improve commercial carrier crash data in West Virginia including coal trucks. All organizations and agencies involved with commercial carrier safety need ready access to basic data describing the crash-involved operator, vehicle, and environment. Such data are necessary to any programmatic or engineering countermeasures. The basic approach used to accomplish the research objectives involved a series of regional meetings where law enforcement personnel expressed their opinions about ways to improve commercial vehicle crash data quality. These results were then weighted and prioritized. The top five solutions generated at these meetings were: 1) In-Service Training 2) Training at West Virginia State Police Academy 3) "Cheat Sheet" 4) On-Site Fatal Team available for crashes involving commercial vehicles and 5) Roll Call Materials. 


\section{ACKNOWLEDGEMENTS}

The author would like to thank the Federal Motor Carrier Safety Administration (FMCSA), West Virginia Public Service Commission (WVPSC), and National Research Center for Coal and Energy for sponsoring this research. The author would like to especially thank the research advisor, Gary Winn, Ph.D., for his extensive help on the project. The author would also like to thank the members of the advisory committee: Hema Siriwardane, Ph.D., Ronald Eck, Ph.D., and Jim French, Ph.D., for their suggestions and help. The author also would like to thank the law enforcement personnel and others who participated in the meetings. 


\section{Table of Contents}

ACKNOWLEDGEMENTS

TABLE OF CONTENTS ............................................... iv

LIST OF TABLES .................................................... v

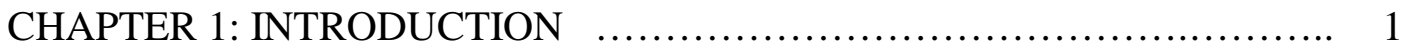

1.1 Introduction .................................................. 1

1.2 Problem Statement................................................. 7

1.3 Project Objectives........................................... 7

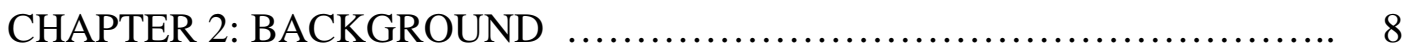

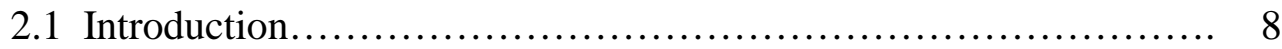

2.2 Responses to the Crash Data Problem............................. 11

2.2.1 Federal Responses ................................... 11

2.2.2 State Response Crash Data Improvement ............... 16

2.3 Technology Improvements in Crash Data Acquisition................ 20

2.4 Other Responses to Data Quality ................................ 23

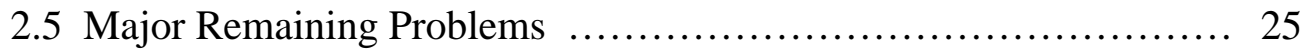

CHAPTER 3: METHODS …............................................ 27

3.1 Introduction ......................................................... 27

3.2 IRB Procedures ................................................. 28

3.3 Location of Meetings ........................................... 28

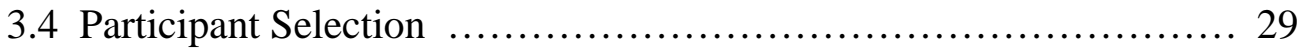

3.5 Response Rate ..................................................... 29

3.6 Data Collection .............................................. 30

CHAPTER 4: RESULTS …........................................... 32

4.1 Discussion of Solutions ........................................ 32

4.2 Results by Location ........................................... 35

4.3 Discussion of Issues/Problems that Received No Votes .............. 36

CHAPTER 5: CONCLUSIONS .......................................... 40

REFERENCES ....................................................... 44

APPENDICES ............................................................. 46

Appendix A - Pre-1997 Commercial Vehicle Supplement Form ........... 47

Appendix B - West Virginia Uniform Traffic Crash Report Form ........ 49

Appendix C - Sample Meeting Agenda ................................ 54

Appendix D - Institutional Research Board Approval Form .............. 56

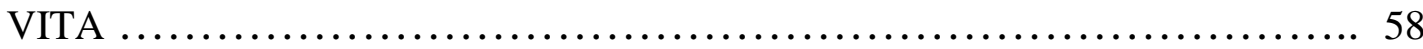




\section{List of Tables}

Table

Page

Table 1: State or Federal Databases Related to ................. 10 Commercial Vehicles

Table 2: Response Rate $\ldots \ldots \ldots \ldots \ldots \ldots \ldots \ldots \ldots \ldots \ldots \ldots \ldots \ldots . \ldots \ldots$

Table 3: Clarksburg Meeting Results ....................... 37

Table 4: Keyser Meeting Results ........................... 37

Table 5: Winfield Meeting Results ......................... 38

Table 6: Logan Meeting Results $\ldots \ldots \ldots \ldots \ldots \ldots \ldots \ldots \ldots \ldots \ldots \ldots \ldots . \quad 38$

Table 7: Combined Full List of the Three Meetings ............... 39 


\section{CHAPTER 1: INTRODUCTION}

\subsection{Introduction}

The National Governor's Association (Richards and Sullivan, 1991) provided the generally accepted definition of a commercial vehicle as:

- A truck with at least 6 tires in contact with the road surface; or

- A vehicle displaying a hazardous material placard; or

- A bus with seating for more than 15 people, including the driver.

A carrier is best defined as: the agent who causes the load to be moved. The carrier can be the driver; a rental agent; the owner and not the driver; or a third party such as a subleaser. Precise determination of "carrier" often requires examination of many levels of documentation. The driver is defined simply as the person behind the wheel.

Trucks are a very important part of the nation's economy, being involved in the majority of freight movement trips in the country. Their significance in the economy is growing. "The number of vehicle-miles traveled annually by large trucks has increased from 148 billion vehicle-miles in 1989 to 191 billion vehicle-miles in 1997" (Scheinberg, 1997). "Today, more than 400,000 domestic motor carriers operate in excess of 4 million tractor-trailers on U.S. roadways" (Pfefer and Neuman, 1999).

The problem of multi-vehicle crashes associated with the booming growth of commercial carriers has grown as well. In 1997, large trucks comprised 7 percent of all vehicle miles traveled and made up only 3 percent of all registered vehicles in the United States. 
"In multi-vehicle crashes, large trucks represented:

- 9 percent of all vehicles in crashes

- 2 percent of all vehicles in injury crashes

- 4 percent of all vehicles in property damage only crashes"

(Large Truck Crash Profile, 1998).

In West Virginia, commercial vehicles and especially coal trucks represent an important part of the state's economy. West Virginia accounted for approximately 1 percent of the value and 2 percent of the weight of all U.S. shipments in 1993. The Commodity Flow Survey (CFS) measured \$35 billion of good shipments weighing 234 million tons in West Virginia. The main commodities by value were: chemical or allied products $(17.4 \%)$ and coal $(12.8 \%)$. The main commodities by weight were: coal $(67.6 \%)$ and petroleum or coal products $(16.7 \%)$. Coal and coal products comprise $84.3 \%$ of the commodities by weight shipped by freight in and out of West Virginia. Sixty-five percent of the value and 29 percent of the weight of these commodities were moved by trucks in West Virginia. (USDOT, 1996)

According to 1997 National Accident Sampling System-General Estimating System (NASS-GES) estimates, 444,000 large trucks were involved in crashes (Scheinberg, 1999). On average, about 700 commercial vehicle operators and 4000 passenger car occupants die annually in two-vehicle crashes involving a large truck and a passenger vehicle. "Fatality rates had been dropping until 1992, and the 1997 fatality rate represents a 20 percent increase in fatalities from 1992" (Large Truck Crash Profile, 1998). The crash involvement rate for large trucks in fatal crashes (number of vehicles 
involved per 100 million miles traveled) in 1997 was slightly higher than the rate for passenger vehicles.

Even though trucks are involved in fewer crashes per mile traveled than are cars, crashes involving large trucks are more likely to result in a fatality. It is not surprising that when commercial vehicles collide with other vehicles, especially cars, the occupants of the passenger vehicles are more likely to suffer injuries. "In 1997, 5,355 people died in crashes involving a large truck and another 133,000 were injured. Of these, 98 percent of the fatalities from crashes between a truck and a passenger vehicle were occupants of the passenger vehicle" (Large Truck Crash Profile, 1998).

The basic tool of a crash data gathering system, the accident report form, provides a blueprint for the information gathering process. The accident report form collects basic facts to be gathered for every crash that will be made available later if the crash is thoroughly analyzed. Because the form serves as a checklist to ensure that essential information is obtained, it should provide for accurate recording of important accident information, yet be as easy as possible to complete and analyze. The value of crash data is to permit analysis of crash circumstances, to pinpoint high-risk situations and possibly suggest a remedy to some crash locations (Bowman and Hummer, 1993).

Crash and other safety data can be used:

- To identify high accident locations and situations

- To identify potential countermeasures to reduce crashes

- To prioritize safety improvements

A highway incident involving commercial vehicles investigated by a police officer in any state must be reported according to state laws on a standard accident form, which 
is developed and maintained by individual states. West Virginia's reporting threshold is established from the National Governor's Association (Richard's and Sullivan, 1991) which defines a reportable accident as an accident that results in:

- One or more fatalities; or

- One or more nonfatal injuries requiring transportation by a vehicle for the purpose of obtaining immediate medical treatment; or

- One or more of the vehicles being removed from the scene due to "disabling damage"; or

- One or more vehicles requiring intervening assistance before proceeding under its own power.

A study conducted by the West Virginia Public Service Commission (Bitner, 2000) reported that certain data elements on the current West Virginia uniform crash report form are often inaccurate or incomplete on the form. The most incomplete elements on crash reports are mainly carrier information, followed by "second carrier" information. A second carrier is a carrier that "subleased" a job from the initial carrier called upon. Carrier information is important because once the information is placed in a state or federal database, it helps to identify the owners or lessors who may be operating unsafe vehicles, out-of-service vehicles, etc.

In 1992, a total of seventeen data elements for commercial carriers were added on a supplemental crash form to be completed by West Virginia enforcement personnel investigating the crash. This supplemental form (included as Appendix A) was printed on green paper to differentiate it from other forms. In 1997, this supplemental commercial vehicle crash form was completely integrated into the revised West Virginia uniform 
crash report form (included as Appendix B). Currently, this is the crash form used by investigating officers in West Virginia (Winn and Bucy, 1997).

Another West Virginia study (Thornton, 1999) suggests other problems exist in collecting crash data in West Virginia. In no order of priority, they are:

- Determining the most harmful event

- No instructions for extent of damage.

- The sequence of events is difficult to follow

- Insurance agent name is not listed on card

• "Had collision with" section

- EMS information

- Hazardous materials section (ex. Yes/No box)

- Mile post needed to determine location of the crash.

According to Thornton (1999), the size and complexity of crash reports presents a problem to some officers. Streamlining report forms to include only the data items actually needed and used, particularly for property-damage only accidents may alleviate this problem. The location of the crash is the single most difficult problem for projectlevel work, because police often use the street names instead of the required route number and highway route when filling out the accident form. The location (measured distance from a reference point) frequently is missing or wrong.

In order for scientists and engineers to address the growing number of heavy truck crashes and to plan countermeasure programs, an extensive database must be available, consisting of factual, accurate information, which describes a large number of these crashes. Crash data, i.e., the collection of data by police officers at an accident scene 
needs to be accurate, complete, and collected and transmitted to the Department of Motor Vehicles in a timely fashion. With complete and accurate crash data, scientists and engineers can begin to change conditions, equipment, and regulations affecting the heavy truck industry.

In summary, the available statistics indicate that: 1) The number of vehicles and number of miles traveled in the commercial vehicle industry has increased rapidly in the last decade by the (Large Truck Crash Profile, 1998). 2) The accident-rate of commercial vehicle crashes is increasing (Large Truck Crash Profile, 1998). 3) In a multi-vehicle crash, the likelihood of a fatality in the involved passenger vehicle is higher (Large Truck Crash Profile, 1998). Therefore, commercial carrier accidents have recently drawn attention from the media, legislators and safety agencies. Quality crash data is key to progress in improving safety through programmatic change, regulatory change, and highway design. 


\subsection{Problem Statement:}

Organizations and agencies involved with heavy truck safety need to have ready access to basic crash data. Basic data describing the crash-involved operator, vehicle, carrier, and environment are necessary to any programmatic or engineering countermeasures. Yet, as has been described (Bitner, 2000 and Thornton, 1999), fundamental crash data for commercial carriers in West Virginia is still plagued by accuracy and timeliness (returning filled-out reports) problems.

This study identifies and prioritizes potential solutions to commercial vehicle crash data quality issues specifically accuracy, timeliness, and completion (missing data elements) in West Virginia, and recommends solutions to the problems based on input from West Virginia law enforcement personnel. This study also identified and prioritized solutions to coal truck crash data problems since coal trucks haul the most tons of freight moved y highways in West Virginia (USDOT, 2000).

\subsection{Project Objectives:}

A number of specific objectives were identified to achieve the project goals, which was to identify solutions to West Virginia crash data problems. These objectives were to:

1. Conduct a thorough literature review on commercial vehicle crash data.

2. Conduct meetings to discuss commercial vehicle crash data.

3. Evaluate and compile results of regional meetings.

4. Construct weighted list and identify the top five solutions to crash data problems. 


\section{CHAPTER 2: BACKGROUND}

\subsection{Introduction}

This section presents a historical perspective of federal and then state responses to the issue of commercial vehicle crash data. This section represents a literature review of key research in this area. Also examined in this literature review is an analysis of 12 sources of data and/or information which may reference commercial vehicles and/or coal trucks.

Crash data collection has been characterized by problems in data accuracy, delays in report submission, and full completion of forms. According to the Bureau of Transportation Statistics (BTS) (BTS, 1998), the problems of critical crash data can be most simply summarized with the following questions:

- Do we have the right statistics on the right subjects?

- $\quad$ Are the statistics reliable and accurate?

- Are the statistics understandable and accessible for decision-making?

(BTS, 1998)

USDOT provides its position on critical crash data needs by saying that "data gaps arise when statistics fail to be relevant, useable, accurate, complete, valid or timely" (BTS, 1998). BTS goes further in its recent report. It suggests that just having a copious body of crash data may not be good enough to make good decisions for scientists and engineers.

The quality of commercial carrier crash data is dependent on the quality and characteristics of local crash reporting systems as well as local, state, and national crash 
data management systems. Highway and road safety analysis receives considerable attention, and problems such as reporting of nonfatal accidents and a lack of good injury data are widely recognized.

"There is a sizable body of data with which to track trends in transportation safety. The most detailed data are for highway vehicles and modes involving commercial passenger transportation. Significant data limitations remain, however, that hinder informed decisionmaking on safety issues. Data needs include: 1) more uniform reporting of crashes and incidents throughout the nation; 2) comprehensive and consistent measures of risk exposure, especially with respect to hazardous cargo; 3) comprehensive information on the causes of crashes and incidents, including human factors, weather and other environmental factors, and equipment and infrastructure failures; and 4) more accurate and complete reporting of injuries and costs" (USDOT, 2000).

The fact that commercial carrier crash data is sometimes inaccurate, untimely (late) or incomplete has been identified as a significant need by the federal government (BTS, 1998). Improved commercial crash data quality could help identify which programs and engineering changes have resulted in safety improvements and therefore should be continued, and which engineering changes or program modifications have not worked and should therefore be discontinued.

One way to further examine the issue of commercial vehicle crash data is to examine sources of data and information related to "commercial vehicles" and "coal trucks.” The 12 data bases shown in Table 1 represent possible sources of commercial vehicle crash data and/or information. An examination of Table 1 reveals that while the sources contain information related to commercial vehicles, none make specific reference to a "coal truck." The keywords coal truck, coal truck crash data, commercial carrier crash data, coal truck accidents, and accident data were entered into numerous databases (see Table 1) and nothing was found regarding coal truck accident data. 
Table 1: Potential Data Sources related to commercial vehicles

$\underline{\text { Sponsoring Organization/Database Title } \quad \text { Commercial Vehicle? }} \quad \underline{\text { Coal Trucks? }}$

USDOT:

Yes

No

Fatality Analysis Reporting

System (FARS)

USDOT:

Yes

No

Bureau of Transportation Statistics (BTS)

USDOT:

Yes

No

National Accident Sampling System (NASS)

National Transportation Safety Board (NTSB)

Yes

No

National Highway Traffic

Yes

No

Safety Administration (NHTSA):

National Accident Sampling System-

General Estimating System (NASS-GES)

Federal Highway Administration (FHWA)

Yes

No

Federal Motor Carrier Safety

Yes

No

Administration (FMCSA):

National Archives and Records

Administration

University of Michigan Transportation

Yes

No

Research Institute (UMTRI)

Texas Transportation Institute (TTI)

Yes

No

FMCSA: Safetynet

Yes

No

Insurance Institute for Highway

Safety (IIHS)

Yes

No

West Virginia Office of Mine Health

No

No 


\subsection{Responses to the crash data problem:}

\subsubsection{Federal Programs:}

\section{FARS}

One of the oldest federal data bases in existence is the Fatal Accident Reporting System, (FARS) which has been in operation since 1975 by the National Highway Traffic Safety Administration (NHTSA) and contains over 90 variables for describing accidents in which an accident - related death occurs within 30 days (Scheinberg, 1999). FARS is a national database and is considered a reliable source for all fatal highway crashes, including fatal truck crashes. However, FARS includes only fatal crashes, which represent only 1 percent of all truck crashes. FARS relies on law enforcement crash reports which are then condensed by a state FARS analyst as the source of data. One of the weaknesses of FARS is that it does not include a comprehensive list of crash factors nor does it rely on a thorough investigation of the crash scene to pinpoint factors that contributed most heavily to the crash. It should also be noted that FARS considers a large truck as a vehicle with a gross vehicle weight rating (GVWR) above 10,000 pounds (GVWR is the sum of all the individual weight capacity ratings on the power unit and any trailing units.). As a database, FARS does not identify coal trucks as a demographic unit.

\section{SAFESTAT}

SAFETYNET, another federal initiative through the Office of Motor Carriers (OMC formerly in FHWA but now is the Federal Motor Carrier Safety Administration (FMCSA)) is an automated database system used to monitor the safety performance of motor carriers. Any carrier with a high number of violations is identified and often given a more rigorous inspection at weigh stations (Scheinberg, 1997). 
SAFETYNET led to the development of SAFESTAT, which is a computer program that uses performance-based data on crashes, roadside inspections, and compliance reviews to identify problem carriers. SAFESTAT ranks motor carriers on the basis of 4 safety evaluation areas (SEA): 1) crash rates; 2) driver factors, including outof-service violations from roadside inspections; 3) vehicle factors: and 4) safety management practices and policies, including the results of prior compliance reviews and enforcement actions (Scheinberg, 1997). For each SEA, values ranging from zero to 100 are determined for all carriers having sufficient safety data related to that SEA. Each carrier's SEA value approximates the carrier's percentile rank in relation to other carriers. The higher a carrier's SEA value, the worse the safety status is of that particular carrier. Carriers that are ranked in the bottom 25 percent for three or more factors or for the crash factor plus one other factor are targeted by OMC for a compliance review. It should be noted that SAFESTAT weighs the data on the basis of severity and age of event. For example, a property damage only crash that occurred four years ago carries less weight on their scale than a multiple fatality crash that occurred only one year ago. SAFESTAT also ensures that the database contains complete, accurate and timely data through a series of checks that will not allow the system to be exited until all data is complete and correct (Scheinberg, 1997).

The Office of Motor Carriers (OMC) officials believe that OMC accident reporting will improve as local enforcement officers that investigate the crashes become aware that SAFESTAT is using their reports to identify poor performers (carriers), however no data is currently available to support this assumption. OMC officials also acknowledged that if commercial motor vehicle crashes go unreported to SAFESTAT, 
then the carrier ranking would drop (Scheinberg, 1997). This would possibly allow some carriers to avoid being listed among the worst 25 percent of performers, and consequently they would not receive a compliance review. While SAFESTAT is designed to better identify problem carriers by using on-the-road performance data, it depends mainly upon the states to submit complete, accurate, and timely data on reportable crashes and the results of roadside inspections and compliance reviews (Scheinberg, 1997).

To improve the completeness, accuracy, and timeliness of roadside inspection data, OMC has recently provided funding through MCSAP grants to purchase laptop computers and special software known as ASPEN to enable inspectors to download inspection results directly into SAFETYNET's electronic database (Scheinberg, 1997). It is expected that using ASPEN instead of paper forms will improve accuracy because the software alerts inspectors to inconsistent information, particularly if the carrier's name and the entered USDOT number do not match. SAFESTAT could benefit from more accurate and timely crash data in its efforts in identifying carriers with a high number of violations.

\section{Inspection Selection Systems (ISS)}

Another tool to help state inspectors select carriers or vehicles for inspections is Inspection Selection Systems (ISS) which became available in 1995 through FHWA. As a commercial carrier pulls into an inspection area, its USDOT number is entered into ISS and the system immediately recommends whether an inspection should be carried out based on previous data (Pfefer and Neuman, 1999). 
ISS is an example of electronic screening for carrier violations. Electronic screening enables inspectors to focus their attention on non-compliant trucks because the vehicles with the best records, which are enrolled in the system, are able to pass by the weigh/inspection stations without stopping. The potential benefits of electronic screening are that it uses labor and time more efficiently, reduces paperwork, reduces data entry errors, and reduces pollution. It is also believed by FHWA that effective weigh and inspection stations reduce the frequency and severity of commercial vehicle crashes and the reduction of vehicular and maintenance related factors in truck crashes. Electronic screening rewards drivers/carriers that comply with state laws by providing faster delivery times, greater convenience, and increased profits. ISS could also benefit from improved commercial vehicle crash data (Pfefer and Neuman, 1999).

\section{BTS}

The Bureau of Transportation Statistics (BTS) was established in 1995 by the USDOT.

"BTS is mandated to compile and analyze statistics on a broad range of subjects specified in Section 111, Title 49 of the U.S. Code, to determine whether the transportation system and its consequences are are getting better or worse, to explain what is meant by better or worse, and to identify contributing factors to the trends" (USDOT, 2000).

However, of the 18 studies listed on the BTS web page titled "Transportation Studies," none relate to improving the goal of crash data for commercial vehicles or even reference "coal trucks." 


\section{FMCSA}

Congress has remained vigilant and responsive to commercial carrier safety issues. The Federal Motor Carrier Safety Administration (FMCSA) was established in 1999 by the Federal Motor Carrier Safety Administration Act of 1999 and took effect on January 1,2000 . The purpose of this act is to create a federal agency whose charge is to reduce the number and severity of large-truck involved crashes through more commercial motor vehicle and driver inspections, carrier compliance reviews, stronger enforcement, expedited completion of rules, sound research, effective commercial drivers license testing, record keeping sanctions, and to create a specialized, federal agency to address these issues. The stated goal of FMCSA is to reduce fatalities in trucks and bus crashes by 50 percent in the near future. Progress is evaluated twice a year and submitted to Congress annually.

Improved crash data is also one of FMCSA priorities.

"The Administration collects and disseminates safety data concerning motor carriers. Data collected by Federal safety investigators and state partners from roadside inspections, crashes, compliance reviews, and enforcement activities are indexed by carrier. This information provides a national perspective on carrier performance and assists in determining Administration and state enforcement activities and priorities. Combined with data from other sources (including the National Highway Traffic Safety Administration), extensive analysis is performed to determine trends in performance by carrier and other factors such as cargo, driver demographics, location, time, and type of incident. Based on identified trends, the Administration directs resources in the most efficient and effective manner to improved motor carrier safety.

Obtaining commercial motor vehicle crash causation data is a central goal in FMCSA's Safety Action Plan. Congress has provided supplemental funding in the Fiscal Year 2000 for a major new commercial motor vehicle crash causation study. Projects in this area include: 
Develop crash databases to focus on causal and contributing factors in commercial motor vehicle crashes.

Identify and compare crash factors attributed to truck drivers and passenger vehicle drivers in two-vehicle crashes and validate these with crash physical configuration data.

Compile and analyze State in-depth crash investigations of large truck crashes to summarize the causation findings.

Perform a major truck crash causation project in conjunction with NHTSA, beginning data collection in 2001" (FMCSA, 2000).

FMCSA inspectors have the power to take a vehicle out-of-service if the carrier is operating without registration or beyond the scope of registration. Fines up to $\$ 25,000$ and permanent disqualification can be implemented for repeat violators. If the penalties are not paid, carriers may not operate in interstate commerce and risk the loss of their registration. Generally, a violation of safety regulations resulting in minimum penalties may apply to repeat offenders. "A uniform system designed to transport data between states concerning violations of traffic control laws by CDL holders is currently being established" (FMCSA, 1999).

\subsubsection{State responses for crash data improvement:}

Several states have incorporated initiatives over the years to focus on the problems associated with commercial vehicle crash data. The following are examples of what some states are implementing to help solve the crash data problem.

\section{Oregon}

Certain states have dedicated full time positions for "sanitizing" and improving of commercial carrier crash data. For example, Oregon employs an experienced crash 
analyst whose sole job is to check crash information, look for inconsistencies in the data, and follow up with the police or carrier to make the accident report as complete and accurate as possible. Oregon also requires motor carriers to file a report within 30 days if one of their vehicles is involved in a serious crash. An Oregon motor carrier report provides more detailed information than the police report about such things as, the driver, vehicle configuration and the load the truck was transporting.

\section{Iowa}

In a partnership with the FHWA, Iowa developed the National Model Software and infrastructure (Dillinger, 1999). In 1993, Iowa's crash data collection and analysis system was in serious trouble as officers in the field made errors, omitted data or wrote illegibly. The National Model would eliminate handwritten notes, technical reviews for data errors, duplicate keying and delayed access to data through a series of checks implemented into the system.

Several advantages of the National Model may be:

- Data entered only once, by the officer

- Electronic data transfer

- Inspection data ready in 14 days (United States average: 100 days)

- Crash data ready in 8 hours (United States average: 6 months)

Agencies involved in the National Model include FHWA, NHTSA, Iowa Department of Transportation (IDOT) and American Management Systems (AMS). The National Model of Data Collection and Management Technology to Improve Highway Safety is a program with the primary goal of creating and implementing various technologies that can be used efficiently and cooperatively in a statewide effort to 
improve the crash data collection and management processes. The focus of the National Model is improving data acquisition for roadway incidents, leveraging proven technology for law enforcement, streamlining the communication of safety information to key stakeholders, and extending the use of this information for short and long-range safety and law enforcement programs (National Model, 2000).

\section{Mississippi}

Mississippi hired two employees in 1998 dedicated to collecting data on truck crashes and report this data to OMCHS (now FMCSA) by calling officers to clear up any ambiguities, deletions, or handwriting errors. "In 1997, Mississippi reported only 1 of 99 fatal crashes involving large trucks to OMCHS" (Scheinberg, 1999). Once the employees were hired, from September 1998 to March 1999, Mississippi reported 1,657 crashes involving large trucks to OMCHS (Scheinberg, 1999). In comparison, from September 1997 to March 1998, Mississippi had increased its number of reported crashes to OMCHS to 46 crashes, crashes which evidently had not been attributed to commercial vehicles.

\section{Connecticut}

Connecticut is currently using ASPEN. ASPEN is a form of electronic screening that allows inspectors to enter the truck's USDOT number into a database for evaluation. ASPEN then makes a recommendation on whether the vehicle should be inspected.

"ASPEN has substantially increased both the quality and currency of the data available to an inspector at a roadside stop about a vehicle, its driver, and the motor carrier" (Scheinberg, 1999). Crash data collection benefits with ASPEN through improved 
ability to identify crash-involved drivers, and to perform the task in a more accurate fashion.

\section{West Virginia}

West Virginia adopted a commercial vehicle crash supplement in 1992 (See Appendix A), adding seven data elements to the existing ten, which referred to commercial vehicles including coal trucks. West Virginia moved to a mostly scannable crash form in 1997 (See Appendix B), and the Public Service Commission is currently installing laptop computers into their patrol cars for the use of ASPEN. West Virginia also merged the supplementary form and NGA approved commercial vehicle crash data elements to its police report in 1997 and provided training on the new form to some state police and larger municipalities in 1996 and 1997. However, no enforcement agencies are scanning the forms and several agencies have not yet switched to the 1997 form (Thornton, 1999).

In West Virginia, Bittner (2000) identified that commercial vehicle data quality suffers because frequently law enforcement personnel have trouble with certain parts of the crash form, particularly "carrier". This results in both accuracy and completion problems for commercial vehicle sections on the crash form. Thornton (1999) noted that in West Virginia, many localities still do not even use the most recent version of the West Virginia crash form, there is a long lag in time to submit the forms to the West Virginia Division of Highways, and that often the commercial carrier portion of the form is incomplete. 


\subsection{Technology Improvements in Crash Data Acquisition:}

Several technology improvements such as scanners, laptop computers, pen-based computers, and palmtop computers have recently been implemented into several police agencies in the United States to aid in the collection of crash data.

\section{Scanners:}

One option to improve accuracy and timeliness of crash data is to revise the accident report form to resemble test forms given to students in school, which can in turn be run through a scanner. "The Virginia DOT estimated that technicians spent approximately 60 percent of their time at file cabinets prior to the installation of scanners" (Hughes et. al., 1993).

The expected benefits of scanning forms are: timeliness of office reporting and reduction of keypunching. However, use of scanners does not improve timeliness of field data processing or the overall quality of the data in the accident form. Information such as driver's name still has to be hand written. The software cannot read bad handwriting and many local agencies often prefer to continue using the old form (Hughes et. al., 1993).

\section{Laptop computers:}

The municipal police force in Clearwater, Florida is currently using laptop computers for their accident data entry forms. The officers turn in their disks at the end of the each day, which are then reviewed for completeness and accuracy. "Generally, the quality of data has greatly improved, with a reduction in data loss, very little training was involved, and the officers seem to like their laptops" (Hughes et. al., 1993). 
Several counties in West Virginia are interested in computer programs/software for crash data collection purposes. According to an unpublished study, of the 33 counties that took part in a recent survey, 29 of them have access to computers (Thornton, 1999).

The expected benefits of laptop computers include:

- Improved legibility of accident reports.

- Improved timeliness of accident data.

- Improved overall quality of all data elements due to less definition ambiguity.

- Reduction of data input errors and omissions.

- Reduction in the demands on report processing personnel at the central agency.

- Improved information management and accessibility of crash data.

Several of the limitations of laptop computers are:

- Keyboard size is discouraging and difficult to use under some circumstances.

- The initial cost of a laptop computer is high.

- Laptops possess a high potential for damage and are cumbersome outside vehicle.

- Still have some form of scanner limitations, so manual review is still necessary.

- Some people are apprehensive of computers (Hughes et. al., 1993). 


\section{Pen-based Computers:}

Pen-based computers, also known as clipboard computers or electronic tablets are very small in size relative to a laptop. They typically have less electronic storage capacity due to their size.

The expected benefits of pen-based computers are:

- The software performs on-line error checks.

- There is a reduction of in-office data entry.

- Pen-based computers operate with removable RAM cards instead of hard disks.

- Weighs only 3-5 pounds and the typical size is 9" x 13", which makes it more convenient to use than laptop computers.

- Eliminates keyboard applications.

Some of the limitations of pen-based computers are that they are costly and officers may still leave portions of the crash form incomplete (Hughes et. al., 1993).

\section{Palmtop Computers:}

Palmtop computers basically are hand-held computers with hand-held data entry terminals. Generally, they are designed by manufacturers for a specific data entry task and they are equipped with removable storage devices or a data link for transferring the information to a larger computer in the office. 
The expected benefits of palmtop computers are:

- They are relatively inexpensive.

- Small size (fits in the palm of the hand or pocket).

- Pen-based computers can 'learn” to read handwriting

- They can easily perform "state specific" operations.

Some of the limitations associated with palmtop computers are:

- The small keypads may make data entry difficult.

- They possess limited storage capacity.

- Only a few lines of screen space are displayed at one time (Hughes et. al., 1993).

\subsection{Other responses to data quality:}

One of the missions of the National Governors Association (NGA) is to provide leadership in the development of a national policy to ensure effective highway safety programs. In response to a congressional directive in 1990, the NGA and FHWA developed the National Truck/Bus Accident Data Program in 1991 to encourage police agencies to collect crash data related to commercial carriers. Working with the National Highway Traffic Safety Administration (NHTSA), this program standardized the definition of "truck" and "bus" and includes at least 17 data elements to evaluate commercial carrier safety. Part of the program was to identify data elements that law enforcement personnel could be trained to collect in an accurate and timely fashion.

West Virginia instituted the NGA recommendations in 1991. At that time, a commercial vehicle supplement to the crash form and training materials for commercial 
carrier crash data in West Virginia was developed by Winn and Bucy (1997) of West Virginia University to provide NGA-based instructional material associated with the current crash form. The training material, which instructed West Virginia enforcement personnel in the use of the form discusses key terms and defines exactly what is considered as a "reportable" accident and the type of vehicle considered as a "truck". The training material also contains an in depth explanation of each section of the crash form as well as several examples to serve as a memory cue. Approximately 100 trainers were trained to deliver the information to local enforcement in West Virginia.

In 1997, Winn and Bucy of West Virginia University developed and submitted a revised version of the commercial carrier data form to the West Virginia Division of Highways. A total of 120 revisions were made to the accident form on the basis of focus groups of police personnel opinions including the merger of the supplement for commercial carriers with the crash form itself. The opinions were collected through a series of 13 meetings throughout the state and telephone surveys. From these opinions, a new crash from was developed and tested in a mock crash trial format. The form was then field tested for 120 days and no difficulties were encountered. The West Virginia Uniform Crash Report shown in appendix B is the current commercial vehicle crash form used by police officers.

Even with these improvements, some police agencies are still not using the updated form, data elements are left incomplete or missing, and the reports are taking as long as six months to be delivered to the West Virginia Division of Highways (Thornton, 1999). 


\subsection{Major Remaining Problems:}

\section{Report Processing Time}

West Virginia law requires investigating officers to turn in the accident report to their supervisor within 24 hours after the investigation is complete according to Title 17C-4. A specified time frame also needs to be established for the reports to be sent to the Department of Motor Vehicles (DMV). "It should be noted that in several counties in West Virginia, there is a time frame sometimes in excess of three weeks before crash reports are even sent to the Department of Motor Vehicles" (Thornton, 1999).

Thornton (1999) reports that another major problem is, for non-state police agencies, no quality checks are performed on the data forms, such as a check for missing items before the forms are sent to the Department of Motor Vehicles. The State Police attempt to have shift supervisors approve and correct crash form, but Thornton (1999) reports that there are still significant problems.

\section{Coal Truck Crash Data}

The National Research Center for Coal and Energy (NRCCE) was interested in more detail related to coal trucks and coal truck crash data because so much of West Virginia's highway and rural traffic freight consists of coal (BTS, 1996).

However, no state or federal agencies seem to be gathering coal truck (a tri-axle or semitractor and trailer hauling coal) specific data mainly because of definitional difficulties. For example, a tri-axle truck could be hauling coal on one trip and limestone on the next. Using the current crash records system there is no way of determining the degree of any 
real or perceived problem with coal truck safety whether a truck involved in a crash icoal truck or a truck hauling other commodities. In examining a wide variety of sources of data, the researchers sought crash data related specifically to coal trucks and could not find any information. 


\section{CHAPTER 3: METHODS}

\subsection{Introduction:}

The West Virginia Public Service Commission had expressed concerns that commercial vehicle crash data had not yet improved in West Virginia to the level of quality expected. This was with special reference to accuracy, timeliness, and completion. In addition, the National Research Center for Coal and Energy (NRCCE) had expressed similar concerns about the quality and quantity of coal truck crash data. It was decided that because of the mutual goals, a collaboration would serve both purposes.

The research objectives of this study were to: Conduct a thorough literature review of commercial vehicle crash data quality, identify representative geographic locations of the four meetings (Clarksburg, Keyser, Winfield, and Logan) and to invite law enforcement personnel to these meetings concerning commercial carrier crash data. The funding agencies and researchers established the meeting locations. Group meetings were chosen over one-on-one meetings in order to generate a wide variety of solutions and to compile a weighted list of possible solutions. A written survey technique was discussed and subsequently rejected by the funding agencies and researchers because of the need for a group dynamic. Potential solutions to the crash data quality problem were generated by officers themselves and were not influenced by the researchers.

Invitations including a meeting agenda (Appendix C contains a sample meeting agenda) were sent out by mail to the state police, city police, and county sheriffs located in proximity to the four designated meeting locations of Keyser, Clarksburg, Winfield, and Logan. Law enforcement personnel were chosen mainly because they deal with the commercial vehicle accident itself along with the commercial vehicle crash form. 
A single meeting was held in Logan to discuss mostly coal truck accident data to ensure that coal trucks were represented. The results of these meetings were evaluated and compiled, and finally a weighted list constructed to identify the top five solutions suggested by meeting participants to crash data problems. The raw frequency of votes each solution received was also tabulated.

The basic approach used to accomplish the research objectives was to elicit West Virginia law enforcement officer's opinions regarding possible improvements to commercial carrier crash data at a series of regional meetings. Those opinions were structured, weighted, and prioritized. The following description of the research methods provides detail about steps taken in completing the study.

\subsection{IRB Procedures:}

In order to obtain permission to organize public meetings and to control any contact with human subjects, the Institutional Review Board at West Virginia University had to review and approve the type of information being solicited from the participants. IRB approved the sample meeting agenda (The approval form is shown in Appendix D). Since the meetings were designed to collect data from the enforcement personnel, there were no specific questions for participants identified beforehand.

\subsection{Location of meetings:}

Meetings were held in Winfield, Keyser, Logan, and Clarksburg. These cities were selected because they were close to interstates (I-64 and I-79) and corridor highways (US 50 and US 119) and convenient to a large number of sheriffs, state police, and 
municipal enforcement personnel. The meeting locations were suggested informally and subsequently agreed to early in the research process by the principal investigator and personnel from the funding agencies, FMCSA and WVPSC.

\subsection{Participant selection:}

Representatives of county sheriff departments, city police, and state police were invited based on proximity to the four cities. Sheriffs were invited from each county in the vicinity of the meeting location and other participants were selected based on the meeting with the Public Service Commission. In addition, personnel from municipal police departments and local state police detachments were also invited. Enforcement officers were invited to attend the two-hour meeting whose purpose was to identify possible solutions to the problems associated with commercial vehicle crash data quality. Each participant was told in the letter of invitation that the meetings were voluntary and that their opinions would be used to help FMCSA and state agency personnel develop a plan to improve commercial vehicle crash data quality.

\subsection{Response Rate}

Of the 103 officers initially invited, a total of 29 law enforcement volunteers attended the meetings in Keyser, Clarksburg, Logan, and Winfield. Table 2 shows the response rates by location. 
Table 2: Response Rate

\begin{tabular}{|c|c|c|c|}
\hline Location & Invited & Attended & $\underline{\text { Response Rate }}$ \\
\hline Clarksburg & 25 & 8 & $32 \%$ \\
\hline Keyser & 10 & 3 & $30 \%$ \\
\hline Winfield & 51 & 10 & $19.6 \%$ \\
\hline Logan & 17 & 8 & $47 \%$ \\
\hline & 103 & 29 & $28 \%$ \\
\hline
\end{tabular}

\subsection{Data Collection:}

The same format was used for all four meetings. First, introductions were made where those present stated their name and affiliation. Sign-in sheets with spaces to fill in phone numbers and e-mail addresses were then circulated. A brief history of crash data improvements in West Virginia was presented with an emphasis on commercial carriers including NGA work and the West Virginia commercial carrier supplement from 1992. Also discussed were the recent creation of FMCSA, and two timely surveys conducted by Bitner (Bitner, 2000) and Thornton (Thornton, 1999). The basic goal of the meeting - to obtain a list of solutions to improve commercial truck crash data was highlighted. In the Logan meeting, the focus was on identifying ways to improve crash data for only coal trucks.

The floor was then opened to discussion from the law enforcement personnel and West Virginia-specific solutions to crash data quality were identified spontaneously by the officers. The researchers responded to questions but did not suggest or favor any particular solution. These solutions were then organized and summarized in no particular 
order on flip-charts at the front of the meeting room. After about one hour of discussion concerning commercial carrier crash data problems/solutions, officers were then asked to vote (prioritize) the solutions by identifying their first, second, and third priority anonymously on a sheet of notebook paper. The researchers then weighted the solutions by assigning five points for a first place vote, three points for a second place vote and one point for a third place vote. In addition to the weighted scale, the raw frequency of votes each solution received was tabulated. After voting was complete the results were reviewed with the officers. Finally, the meeting was adjourned and each officer was thanked for his/her participation. 


\section{CHAPTER 4: RESULTS}

This section presents a discussion of all the possible solutions generated at the four meetings as well as a discussion of issues/problems identified at the meetings. Due the varying backgrounds of the participants some possible differences in the meeting results are also discussed. Then the results from each meeting are presented as well as a final composite list from the four meetings.

\subsection{Discussion of Solutions:}

\section{Improved training on commercial carrier crash data at the West Virginia}

State Police Academy. All West Virginia law enforcement officers currently receive basic training at the Academy, but officers participating in the regional meetings felt the training on commercial carrier crash data is not covered in enough detail during the basic indoctrination. Gary Winn of West Virginia University is currently working with the State Police Academy in an effort to implement in-depth training on commercial carrier crash data at the Academy. Coal trucks, per se, are not covered in Academy training and special training could be developed to obtain coal truck crash data. For example, the state police at the Logan meeting suggested that GVWR plates on coal trucks are often obscured by mud/dirt, but the usual location of important numbers on the coal truck could be the topic of instruction.

In-Service training. In-Service training is any continuing education activity, and normally follows a lecture/discussion or hands-on format. All local level law enforcement personnel in West Virginia are required to complete eight hours of in-service 
training every year. A period of training on the commercial carrier data elements could be implemented as a part of in-service training. In-service training, could focus at least one hour on commercial vehicle crash data and in the southern part of West Virginia could focus on obtaining coal-truck crash data (location of GVWR plates for example). This training could also be conducted by regionally-located, senior-level WVPSC officers.

On-Site Fatal Accident Investigation Team solution was identified only at the Winfield meeting. This proposed team would consist of a multi-disciplinary group of trained personnel stationed at various locations throughout the state. Whenever a fatal crash involving a commercial vehicle occurs, the fatal team members in that area would be notified and sent to the scene of the accident to provide a thorough accident investigation to supplement the standard accident report forms.

Daily or weekly Roll Call or monthly V-TAP. During roll call (the $10-15$ minute break between shift changes) or V-TAP (state police version of roll call, which occurs once a month), some sort of supplement or review would be implemented related to the proper way to fill out the heavy truck crash elements and location of items on the form. These materials and examples are now available in part in the training materials developed for the Division of Highways in 1997 (Winn and Bucy, 1997).

Content. Improving or clarifying course content relative to heavy trucks during training (In-service, State Police Academy, Roll Call, etc), such as more examples on carrier information could benefit improved commercial carrier crash data.

Video. An instructional video related to locating information on a truck such as where to find the USDOT number or how to determine "carrier" data could serve as a 
memory cue to remind officers of the number locations on the commercial vehicle and “carrier" determination could be identified or developed.

“Cheat Sheet.” A laminated pocket-sized instructional guide could be placed in a wallet or citation booklet of law enforcement personnel to serve as a reminder of how to fill out the crash form and locate items on the trucks. Such a "cheat sheet" is available for a collision between a train and a motor vehicle. A "cheat sheet" for commercial vehicle accidents could easily be developed.

Incentives/Penalties. Currently, their is no incentive for a local governmental entity to complete a crash form accurately and to submit it in a timely manner, nor are there any state penalties if a form is not completed correctly or in a timely matter. Late or incorrect forms are not subject to penalty. A possible penalty or incentive could be developed to encourage timely and accurate completion of the crash form.

Electronic Accident Report Form. Officers suggested that an electronic form (possibly stored as software on a laptop of desktop computer) would eliminate the need to complete the forms by hand as well as transfer of data problems and would also prompt responses, block incomplete data elements, and present stored memory cues. However, such implementation would be costly and require training.

1-800-CALL-PSC. Develop a PSC 1-800 number that police officers can call 24 hours a day to ask questions when a traffic accident occurs involving a commercial carrier.

Coal Truck/Logging Truck Silhouette. Law enforcement personnel at the Logan meeting suggested that a simple silhouette added into the crash form of a coal or logging truck accompanied with arrows pointing to the location of important numbers 
such as USDOT or VIN would be beneficial. A "coal truck" or "logging truck" checkbox was also suggested to be implemented into some open space on the current crashform.

Supplemental Form. The development of supplemental crash form for coal, logging, or limestone trucks.

PSC to help fill out the form. Inspectors of the Public Service Commission could be called when a crash involving a commercial vehicle occurs to help fill out the commercial vehicle section of the crash form. The public service commission inspectors are familiar with the locations of items on the truck and could be beneficial in determining "carrier" information.

\subsection{Results by Location:}

Each of the four meetings resulted in a lively interchange of expert solutions to commercial vehicle crash data problems. At each meeting, enforcement personnel needed little encouragement to begin making suggestions. Tables 3, 4, 5 and 6 present a list of the prioritized results from each of the four meetings and Table 7 presents a combined list of the prioritized results from all four meetings. Differences in solutions at the meetings may be attributed to the varying backgrounds of the participants as well as number of participants, for example, there were more PSC members at the Winfield meeting and more state police at the Logan meeting compared to other locations. The representation of PSC members at the Winfield meeting was attributed to the possible solution of an On-Site Fatal Accident Investigation Team, which was not brought up at 
the other meetings. However, at every meeting, solutions such as In-Service training, and Training at the State Police Academy rose to the top.

\subsection{Discussion of Issues/Problems that received no votes:}

Discussions at the meetings identified a number of issues relative to improving crash data even though they received no votes. It was felt by the researchers that these concerns warranted at least some discussion in this report. Several of the more prominent of these are discussed below:

No exposure to state crash form. Certain local level law enforcement officers have never been exposed to the 1997 form training, this issue actually goes back to training at the Academy and In-Service training.

The low frequency of crashes involving commercial vehicle or coal trucks heightens the problem. It was learned during the meetings that officers located in rural areas of the state may investigate a crash involving a commercial carrier only once every few years. Some enforcement personnel may investigate a coal-truck crash even less frequently. Consequently, they lose their familiarity with and understanding of the motor carrier supplement and even if they had the best possible Academy exposure, simple infrequency of use causes skills to deteriorate.

A number of participants pointed out that carrier information may not be readily apparent to those outside the motor carrier industry because "Carrier" data is exclusive to the heavy truck industry. It is not always the driver of the truck and additional examples and explanations are needed. Identifying the "carrier" can be difficult for law enforcement personnel to determine under the very best conditions, and 
may involve two, three, four, and even five steps backward in time to sort out "carrier". This might mean extra investigation time for the officers and therefore the item is omitted due to time constraints. The difficulty of determining "carrier" came up at each meeting.

Table 3: Clarksburg Meeting Results (3/13/00)

SOLUTIONS

1.) In-Service Training

2.) Training at State Police Academy

3.) Roll Call Materials

4.) "Cheat Sheet"

5.) Content
POINTS

14

12

10

5

4
FREQUENCY

4

4

4

1

2

Table 4: Keyser Meeting Results (3/17/00)

\section{SOLUTIONS}

1.) In-Service Training

2.) Instructional Video

3.) Training at State Police Academy

4.) Roll Call Materials

5.) "Cheat Sheet"

\section{POINTS}

11

8

5

1

1
FREQUENCY

4

2

1

1

1 
Table 5: Winfield Meeting Results (3/24/00)

\section{SOLUTIONS}

1.) Training at State Police Academy

2.) On-Site Fatal Accident Investigation Team

3.) In-Service Training

4.) Content

5.) Incentives/Penalties

6.) Roll Call Materials

7.) Electronic Accident Report Form

8.) 1-800-CALL-PSC

\section{POINTS}

20

16

8

5

3

1

1

0

\section{FREQUENCY}

4

5

4

1

1

1

1

0

Table 6: Logan Meeting Results (9/29/00) (Coal Truck Discussion)

\section{SOLUTIONS}

1.) Cardboard/Laminated sheet for memory (Cheat Sheet)

2.) In-Service Training

3.) Training at State Police Academy

4.) Supplemental Form

5.) Coal Truck/Log Truck Silhouette

6.) PSC to help fill out the form
POINTS

26

13

3

0

0

0

\section{FREQUENCY}

6

5

1

0

0

0 
Table 7: Composite List from the Four Meetings

\section{SOLUTIONS}

1.) In-Service Training

2.) Training at State Police Academy

3.) "Cheat Sheet"

4.) On-Site Fatal Accident Investigation Team

5.) Roll Call Materials

6.) Content

7.) Instructional Video

8.) Incentives/Penalties

9.) Electronic Form

10.) 1-800-CALL-PSC

11.) Supplemental Form

12.) Coal Truck/Log Truck Silhouette

13.) PSC to help fill out the form

\section{POINTS}

46

40

32

16

12

1

0

0

0

0
FREQUENCY

17

10

8

5

6

3

2

1

1

0

0

0

0 


\section{CHAPTER 5: CONCLUSIONS}

The literature review suggests that commercial vehicle crashes are growing in frequency in the United States, and that at least in West Virginia, coal trucks represent a significant value and weight of freight hauled in the state (USDOT, 1996). However, only a few national databases have any commercial vehicle crash data and none have coal truck crash data. Crash data quality, and especially in the case of coal trucks, data quality, could be improved. A study was conducted in West Virginia with gathered law enforcement opinions about solutions to crash data quality problems.

The researchers conclude first that the meeting format and open-ended discussion style of data collection was a useful and viable way to gather data. We conclude that while the response rates were somewhat low, enforcement personnel had to be released from work and as such, their participation as volunteers was to be commended. We also conclude that the weight and prioritizing system we used worked well enough to have confidence in our results. The raw frequency of votes each solution received was also documented and as Table 7 presents, the final composite list of solutions is basically the same. The only difference noted was that Roll Call Materials would be the $4^{\text {th }}$ ranking solution followed by On-Site Fatal Accident Investigation Team, on the basis of frequency of votes alone.

This study has identified and prioritized some solutions to improving crash data quality for commercial vehicle accidents in West Virginia. The researchers conclude In-Service training for law enforcement officers in which instructional guides, videos, or classes could be implemented related to commercial vehicle and coal truck crash data collection training could be developed by using in-stock materials. This suggests that 
officers could use "refresher" materials on commercial vehicle crash data from time-totime.

Receiving second priority was more in-depth coverage of commercial vehicle crash data collection at the West Virginia State Police Academy. Some efforts and contacts have been established between West Virginia University and the State Police Academy to implement training on the commercial carrier crash form. In fact, Academy personnel have agreed to strengthen commercial vehicle crash data instruction for all officers who go through the Academy.

Third was the development of a "cheat sheet." This instructional guide could be placed in a wallet or citation booklet of law enforcement personnel to serve as a reminder of how to fill out the crash form and locate items on the truck. West Virginia University could easily develop a "cheat sheet" for commercial vehicles and coal trucks.

Because of the scores received, the researchers believe that efforts should be directed at the first three solutions in the first year following the study. The remaining solutions are far less important and can be implemented as time and resources allow.

The results of the Logan meeting which focused only on crash data related to coal trucks, offered slightly different solutions and these need to be discussed separately. The top ranking solution by far that the officers believed would benefit them the most was a "cheat sheet" for memory that would assist them in filling out the crash form. This "cheat sheet" could identify the number locations on coal trucks. The second and third ranking solutions again focused on training at the State Police Academy and In-service training or roll call. The Logan officers also pointed out that a simple section added to the crash form, which would identify the commercial vehicle as a coal truck, logging 
truck, limestone truck, etc. would benefit engineers, and officers determine the vehicle type at a later date. This "check off" could be added into the existing white space on the crash form, and for the very first time, help identify whether the commercial vehicle was a coal, log, or gravel truck. Furthermore, the Logan officers noted that attention should be given during training to officers getting help in locating coal truck GVWR plates or USDOT number. A silhouette could work in this case and could be added to the current form.

The researchers recommend that these findings be discussed in a future joint meeting between State Police Academy officials, West Virginia Public Service Commission, West Virginia Division of Highways, West Virginia Traffic Records Committee, and West Virginia University researchers. That meeting would determine if and how the results could be implemented. Training and crash form issues would cover all of the results of this research including those related to coal truck crash data.

Future research on improving the quality of commercial vehicle crash data, to include coal truck crash data would include:

- Whether coal trucks are on crash report databases in the future.

- How to address any issues of crash data quality that are unresolved two or three years from now.

Lastly, the focus of this research was on identifying strategies to make law enforcement personnel better capable to complete accident reports. However, it is possible that in certain circumstances, such as accidents involving commercial vehicles, it should be the responsibility of a specialist to conduct the accident investigation. The results of the literature review document many failed attempts to make the officers more 
adept at completing the investigations and reports, including specialists to review the reports. Logic suggests that an accident investigation specialist with an engineering background would be better equipped to report the data that will be critical in conducting engineering analyses, such as accident rate analyses or accident reconstruction's.

A feasibility study of providing an accident investigation specialist could be conducted through comparisons with other industries that already implement this idea, such as in the coal mining industry. In addition, there are a number of issues that need to be resolved to implement this idea. For example, given the demands of removing accidents from the roadway as quickly as possible via incident management, what proximity would the specialist need to the accident to be able to respond and conduct their investigation without causing excessive delay to the overall accident clearance effort? Furthermore, if the constraints from an incident management standpoint dictate that these specialists must be located at numerous locations, then what is the best method of procuring this talent? The frequency of these types of accidents would likely not warrant full time devotion to the effort unless the person could cover a large geographic area, therefore the need for numerous specialists would likely mean some form of privatization of this program. 


\section{REFERENCES}

Bitner, Loretta. "Unpublished Survey Regarding Carrier Information."

West Virginia Public Service Commission. Charleston, WV. 2000.

Bowman, Brian L., and Joseph Hummer. "Data Validity Barriers to Determining Magnitude of Large Truck Accident Problem." Transportation Quarterly. 47 (Jan 1993): 39-60.

Bureau of Transportation Statistics, United States Department of Transportation. Bicycle \& Pedestrian Data: Sources, Needs, \& Gaps. Washington, DC: 2000.

Bureau of Transportation Statistics, United States Department of Transportation. Transportation Statistics Beyond ITSEA: Critical Gaps \& Strategic Responses. Washington, DC: Jan. 1998.

Bureau of Transportation Statistics, United States Department of Transportation. Transportation Statistic Annual Report: 1997. Washington, DC: 1997.

Dillinger, Terry. "Iowa Officers Do Police Work, Not Paperwork." 1999. Harddrive. http://www.aamva.org/Publications/Harddrive/Autoreporting_w99.html. 23 Dec. 1999.

Federal Motor Carrier Safety Administration. Summary of the Motor Carrier Safety Improvement Act of 1999. Washington DC: 1999.

Federal Motor Carrier Safety Administration. 2000. Federal Motor Carrier Safety Administration. http://www.fmcsa.dot.gov/. 28 Sept. 2000.

Hughes, Warren E. et. al. New and Emerging Technologies for Improved Accident Data Collection. FHWA-RD-92-097. Turner/Fairbank Highway Research Center. McLean, VA: 1993.

Large Truck Crash Profile: The 1997 National Picture. Office of Motor Carriers, Washington, DC: Sept. 1998.

"National Model: Statewide Application of Data Collection and Management Technology To Improve Highway Safety." Iowa DOT. http://www.dot.state.ia.us/natmodel/overview.htm. 11 Feb. 2000. 
Pfefer, Ronald C., and Timothy R. Neuman. "Improved Safety Information to Support Highway Design." NCHRP Report 430. National Academy Press, Washington, DC: 1999.

Richards, S.H. and T.D. Sullivan. "National Governor's Association: Truck Accident Data Collection Program." Washington, DC: 1991.

Scheinberg, Phyllis F. "Commercial Motor Carriers: DOT is Shifting to Performance Based Standards to Assess Whether Carriers Operate Safely." General Accounting Office, Washington DC: 3 Nov. 1997.

Scheinberg, Phyllis F. Truck Safety: Motor Carriers Office Hampered by Limited Information on Causes of Crashes and Other Data Problems. General Accounting Office, Washington DC: 29 June 1999.

Thornton, Chastity. "Unpublished Survey Regarding the West Virginia Crash Reporting System." WVFMCSA, Charleston, WV: Oct. 1999.

United States Department of Transportation. "Transportation Studies." 2000. http://www.bts.gov/transtu 28 Sept. 2000.

Winn, Gary L. "Final Report on the Development of an Improved West Virginia Crash Data Report." Submitted to West Virginia Division of Highways. Industrial Management and Safety Engineering, West Virginia University: Dec. 1997

Winn, Gary L. and David S. Bucy. "Technology versus Culture: Improving the Efficiency of Traffic Crash Data Collection in West Virginia." Industrial Management and Safety Engineering, West Virginia University: 10 July 1997.

1997 Large Truck Crash Overview. 1997. United States Department of Transportation. http://www.mcs.dot.gov/factfigs/mchsstats/97overview.htm. 24 Dec. 1999. 


\section{Appendices}




\section{Appendix A: Pre-1997 Commercial Vehicle Supplement Form}


WEST VIRGINIA UNIFORIM TRAFFIC ACCIDENT REPORT COWIMERCIAL CARRIER SUPPLEMIENT THIS FORM IS REQUIRED ONLY WHEN ONE OR MORE OF THE VEHICLES INVOLVED WAS A COMMERCLAL CARRIER AND THERE WAS A FATALITY OR INJURY REQUIRING TRANSPORTATION FOR TREATMENT OB ONE OF THE VEHICLES INVOLVED WAS TOWED OR ONE OF THE VEHICLES WAS PROVDED ASSISTANCE

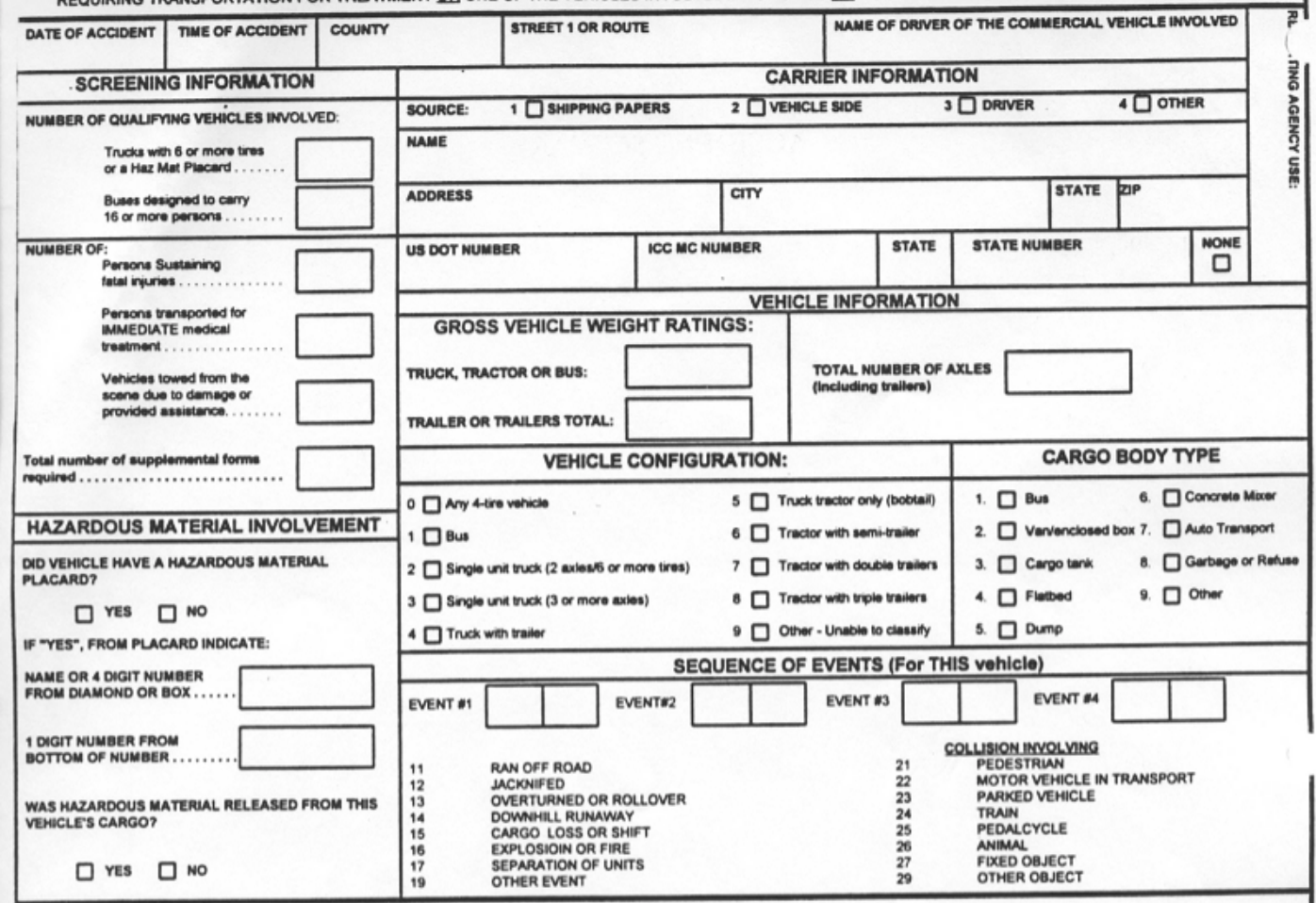

COMMERCIAL CARRIER NARRATVE SECTION 


\section{Appendix B: West Virginia Uniform Traffic Crash Report Form}




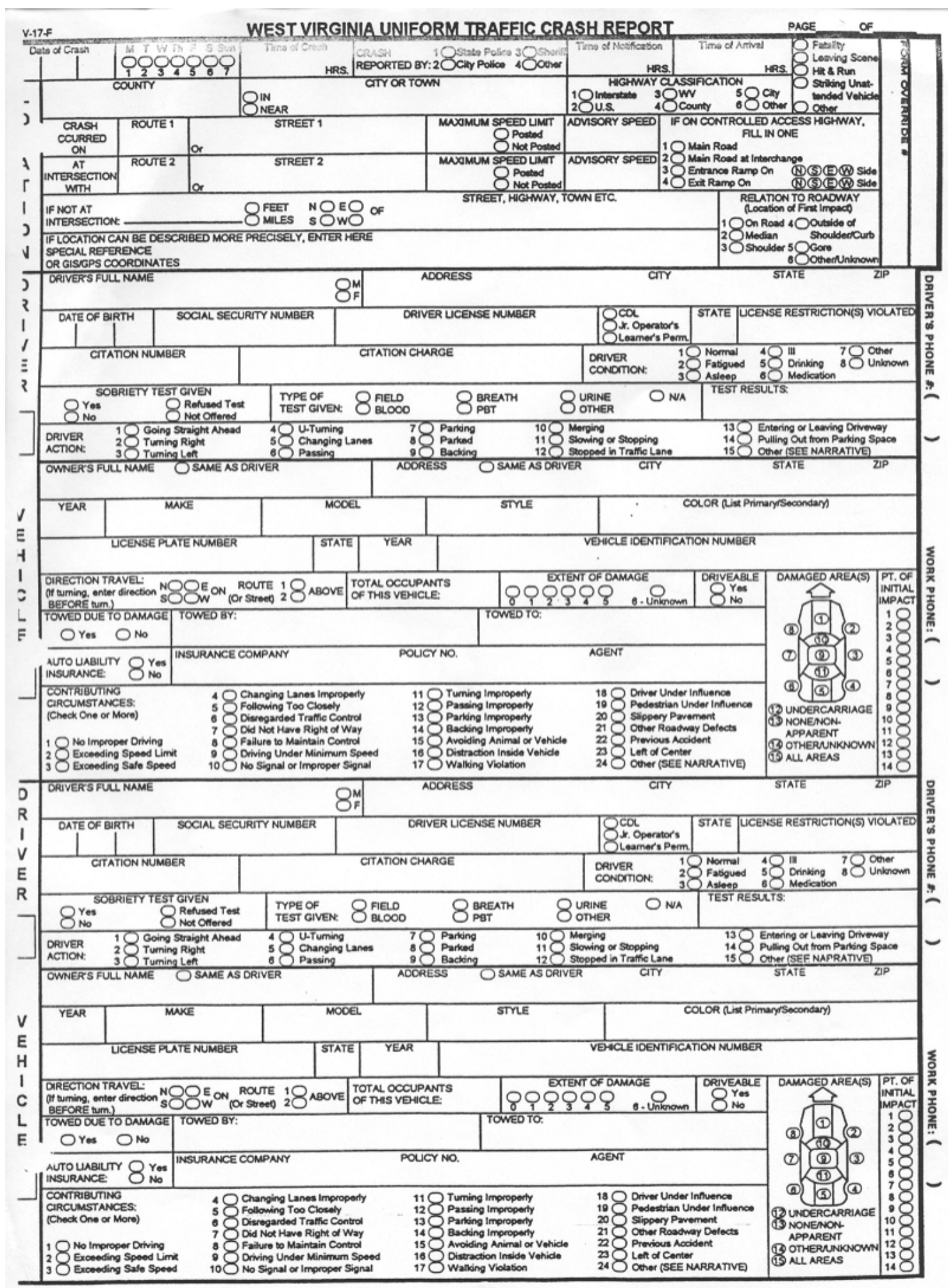




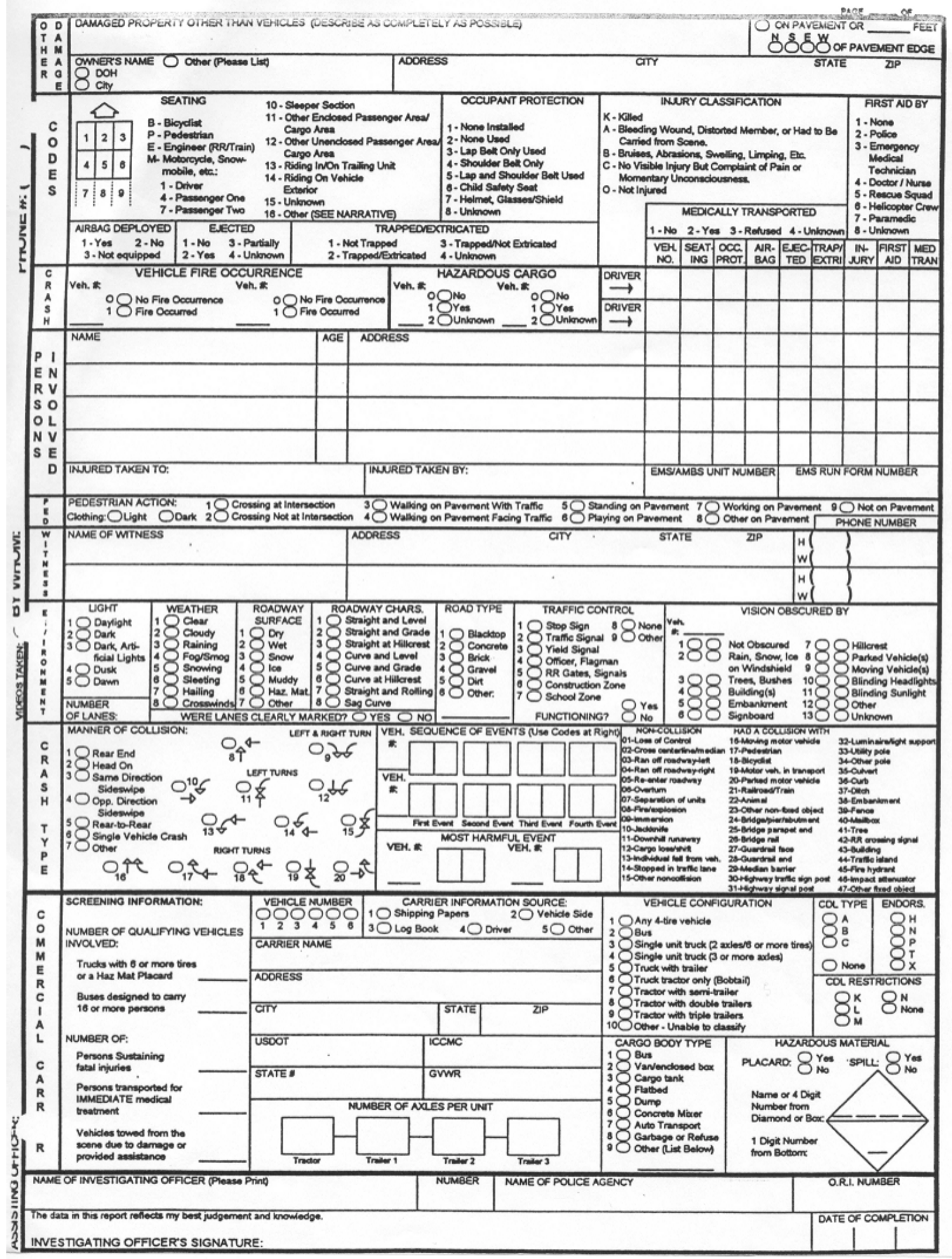




\section{STATEMENTS OF INVOLVED DRIVERS AND WITNESSES (IF AVAILABLE)}

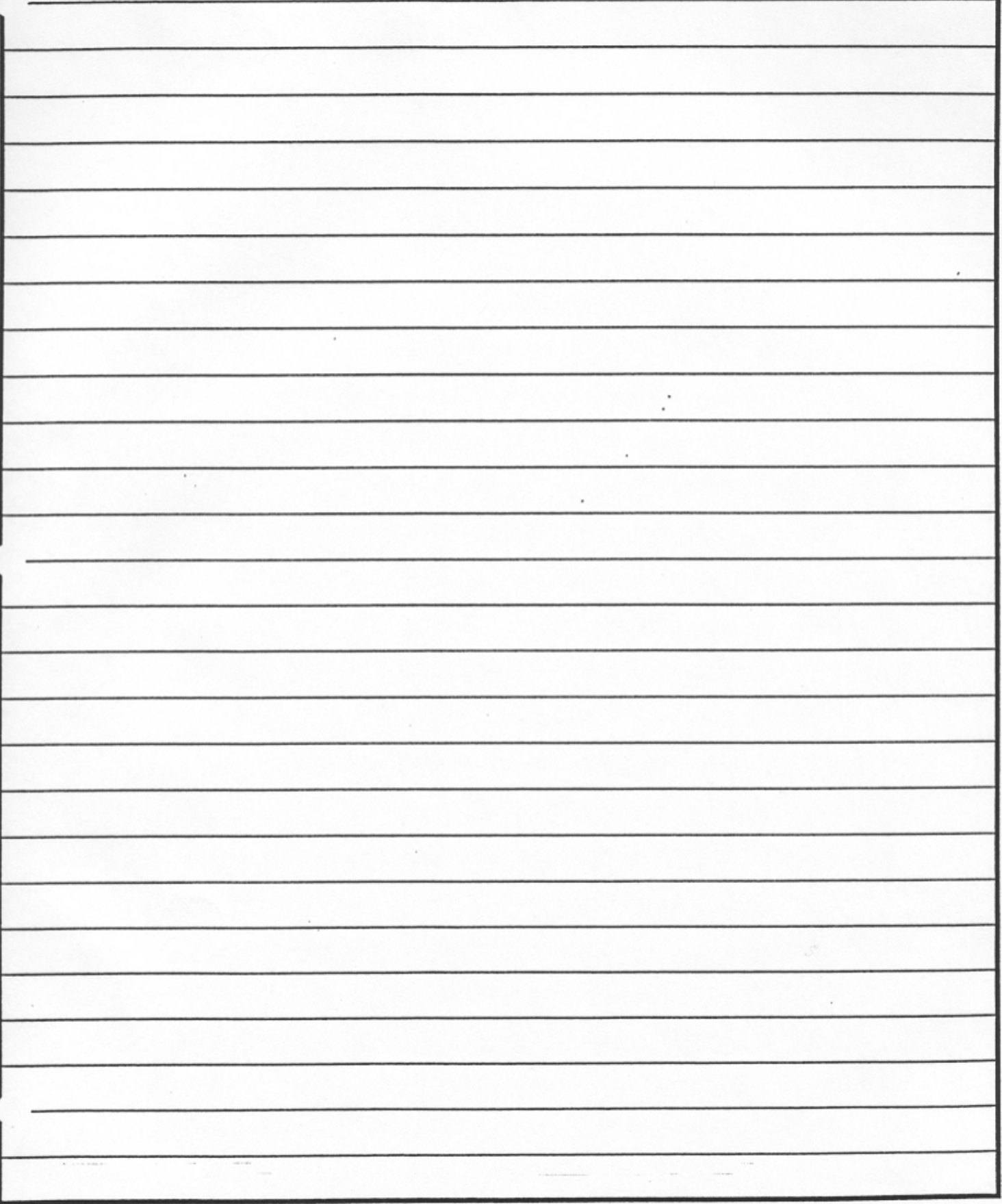

ATTACH ADOMONAL STATEMENT SHEETS AS NEEDED 


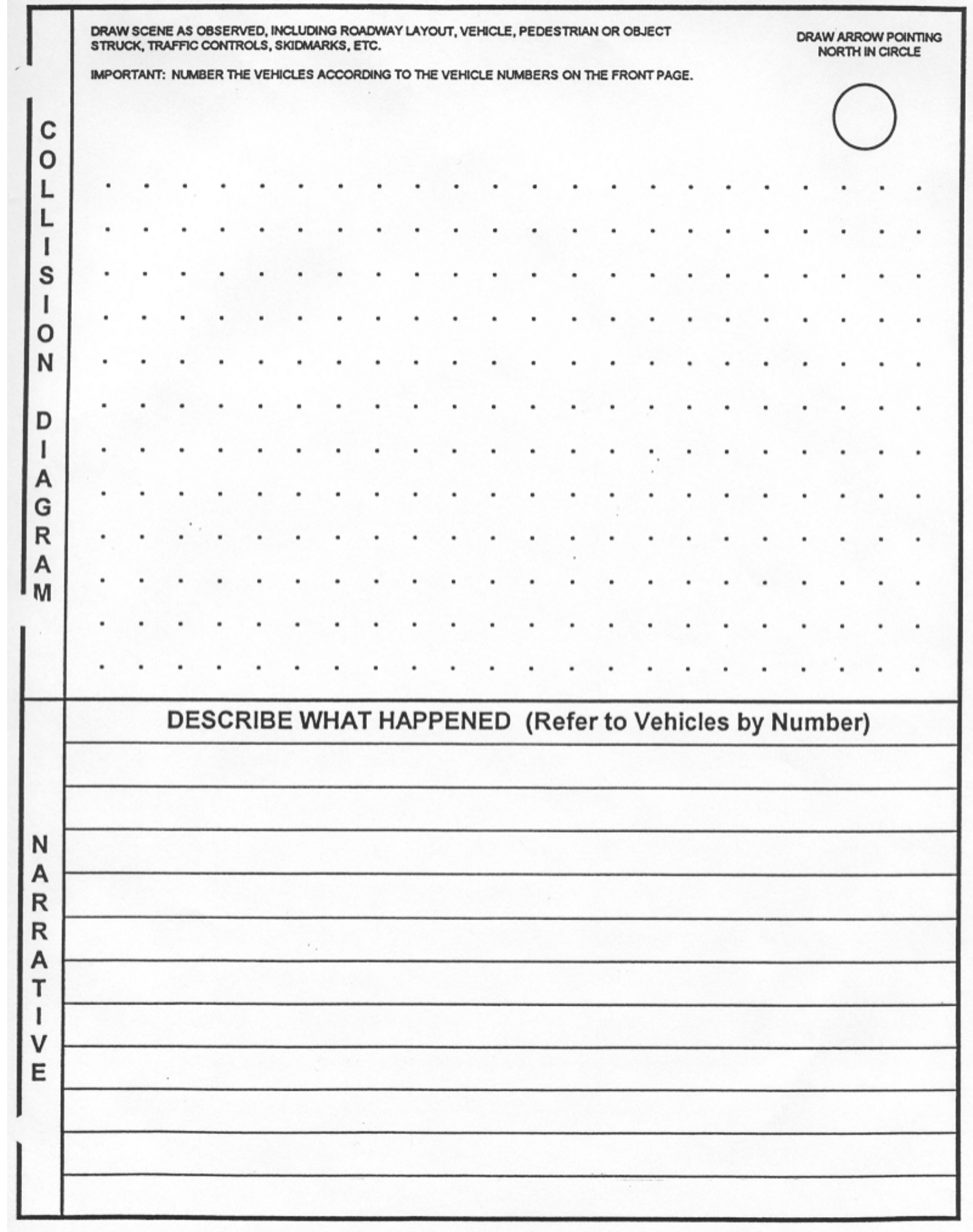


Appendix C: Sample Meeting Agenda 


\title{
WestVirginiaUniversity \\ College of Engineering and Mineral Resources
}

\section{Focus group Meeting: Commercial Carrier Data Quality}

\author{
March 13, 2000 \\ Clarksburg, WV \\ Host: Lt. John Fuscaldo, Clarksburg PD \\ Research Investigators: Gary Winn, Ron Eck, West Virginia University \\ Research Assistant: Kris Gillespie, West Virginia University
}

Agenda:

Introduction of Guests (Winn)

Circulate sign in sheets (Winn)

Goal for today: list of priorities to improve commercial truck crash data

Brief discussion of current state research
FMCSA
C. Thornton
L. Bittner

Open discussion of issues

Summarizing specific problems

Voting on the problem areas

Review of final list of priorities

Future areas of work

Adjourn

Department of Industrial and Management Systems Engineering 


\section{Appendix D: Institutional Research Board Approval Form}




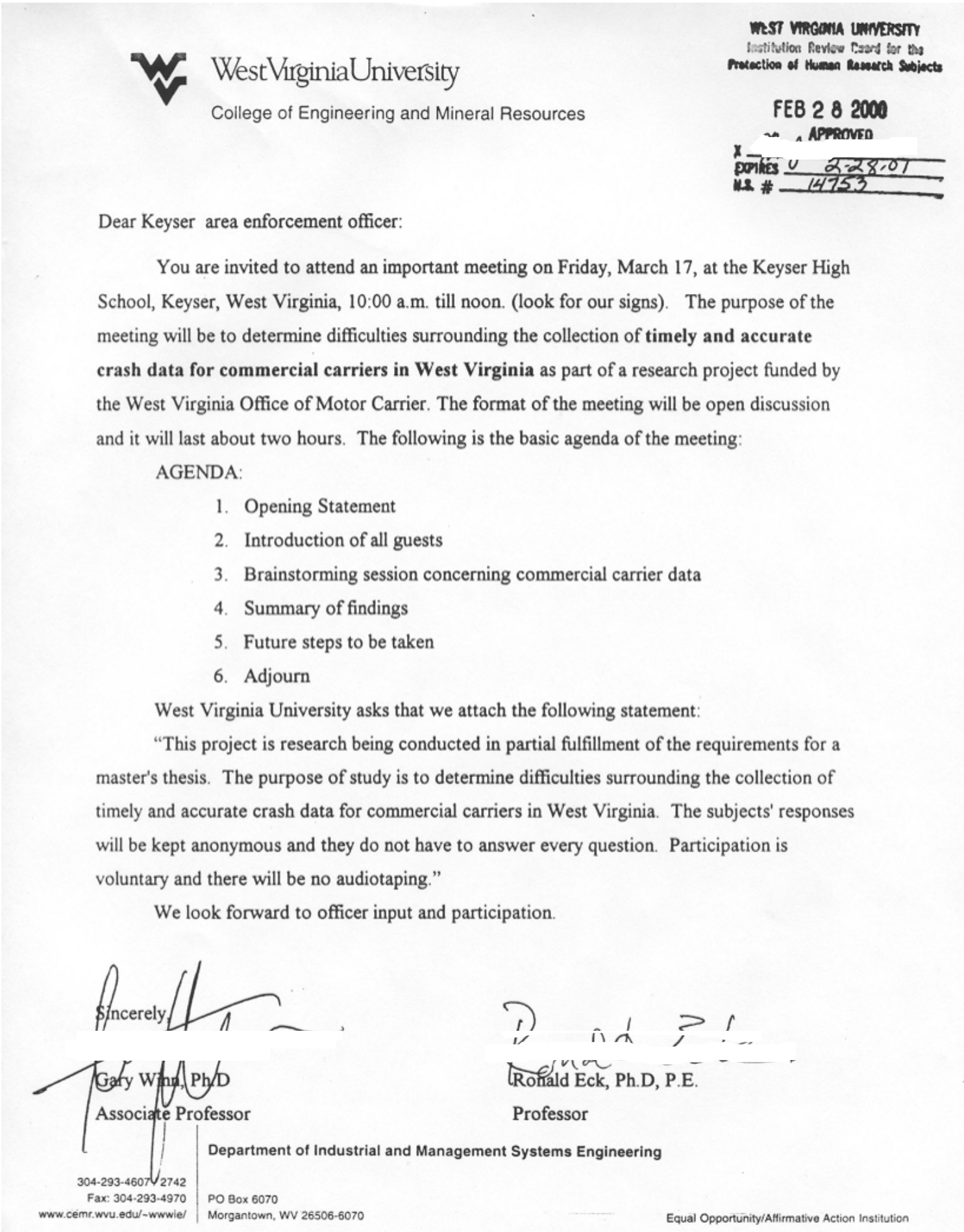




\section{VITA}

Kris Gillespie was born in Parkersburg, West Virginia in 1977. Mr. Gillespie received a Bachelor's Degree in Civil Engineering from West Virginia University in May 1999. Currently he is a Master's candidate in Geotechnical Engineering. 